\title{
Anti-metastatic Activity of Curcumin Analog Pentagamaboronon-0-Sorbitol Against HER2-overexpressed MCF-7 Breast Cancer Cells
}

\author{
Lailatul Qodria ${ }^{1,2}$, Indah Hairunisa ${ }^{1,2}$, Rohmad Yudi Utomo ${ }^{2}$, Adam Hermawan ${ }^{2,3}$, \\ Edy Meiyanto ${ }^{2,3, *}$
}

\begin{abstract}
${ }^{1}$ Master Student of Biotechnology Program, Faculty of Pharmacy, Universitas Gadjah Mada, Yogyakarta, Indonesia ${ }^{2}$ Cancer Chemoprevention Research Center, Faculty of Pharmacy, Universitas Gadjah Mada, Yogyakarta, Indonesia ${ }^{3}$ Departement of Pharmaceutical Chemistry, Faculty of Pharmacy, Universitas Gadjah Mada, Yogyakarta, Indonesia
\end{abstract}

\begin{abstract}
Breast cancer with Human Epidermal Growth Factor Receptor (HER)2 overexpression increases tumor progession and lead to metastasis, which is primarily cause of mortality in breast cancer. Pentagamaboronon-0 Sorbitol (PGB-0-So) is an aquoeous formulation of curcumin analog, PGB-0, with sorbitol. This compound has been developed as an anticancer chemotherapeutic agent and a boron carrying pharmaceutical for boron neutron capture therapy (BNCT). The aim of this study is to investigate anti-metastatic activities of PGB-0-So against HER2-overexpressed MCF-7 breast cancer (MCF-7/HER2) cells. The MTT cytotoxicity assay of PGB-0-So exhibited cytotoxic effect with an $\mathrm{IC}_{50}$ value of $35 \mu \mathrm{M}$. The testing of anti-migration activity using the scratch wound healing assay demonstrated that PGB-0-So inhibited the closure of the wound on MCF-7/HER2 cells compare to the control. Furthermore, PGB-0-So was able to suppress matrix metalloproteinase (MMP)-9 activities, based on the gelatin zymography assay. In conclusion, PGB-0-So has potency to be developed as an anti-cancer agent against metastatic breast cancer.
\end{abstract}

Keywords : PGB-0-So, anti-metastasis, cell migration, MMP-9, MCF-7/HER2

\section{INTRODUCTION}

Human Epidermal Growth Factor Receptor 2 (HER2) overexpression is found in approximately $20-30 \%$ of cases of breast cancer. HER2-positive breast cancer shows worse prognosis leading to aggressive disease that causes chemo-resistant (Yokoyama, et al., 2006) and increased metastasis (Wolf-Yadlin, et al., 2006). Moreover, failure of metastasis prevention primarily caused mortality in breast cancer.
The treatment of metastasis in breast cancer was conducted by chemotherapy, such as doxorubicin which performed strong cytotoxicity against cancer cells. Despite its potent anticancer activity, doxorubicin had several limitations for long-term

Submitted: July 26, 2018

Revised: September 4, 2018

Accepted: September 7, 2018

*Corresponding author: edy_meiyanto@ugm.ac.id 
use including cardiotoxicity and chemoresistance (Carvalho, et al., 2009; Thorn, et al., 2011). In addition, low dose of doxorubicin induces epithelialmesenchymal transition (EMT) and lamellipodia formation leading to metastasis on breast cancer cells (MBC) (Bandyopadhyay, et al., 2010, Amalina, et al., 2017). Hence, several anti-metastatic agents had been developed to treat MBC.

Development of anti-metastatic agents as potential candidate of chemotherapeutic agents has been established over the years. Patients characterized as metastatic HER2-positive breast cancer are treated specifically with anti-HER2 either alone or in combination with chemotherapy, especially taxanes. Unfortunately, specific anti-HER2 therapy, such as Trastuzumab, also caused resistance through various mechanisms (Luque-Cabal, et al., 2016). Similar to doxorubicin, taxanes in low dose induced peripheral neuropathy in breast cancer (Bhatnagar, et al., 2014), while platinum compound, such as cisplatin, induced EMT in ovarian cancer (Baribeau, et al., 2014). Thus, the effective anti-metastatic agents need to be developed further.

Curcumin analog based on benzylidine cyclopentanone backbone such as Pentagamavunon-0 (PGV-0) and Pentagamavunon-1 (PGV-1) exert potent cytotoxic and anti-metastatic activities toward several types of breast cancer cells (Meiyanto, et al., 2014; Putri, etal., 2016). Pentagamaboronon-0 (PGB0 ) is a novel curcumin analog based on benzylidine cyclopentanone and boron atom substitution developed by Cancer Chemoprevention Research Center, Faculty of Pharmacy, Universitas Gadjah Mada (Utomo, et al., 2017). This compound has been developed as an anti-cancer chemotherapeutic agent and boron carrying pharmaceutical for boron neutron capture therapy (BNCT). PGB-0 is reported to be able to interact with HER2 ATP-binding sites and decrease HER2 expression on the MCF-7/HER2 cells (Utomo, et al., 2017). Cytotoxicity of PGB0 toward HER2-positive breast cancer had been determined. PGB-0 also performed anti-metastatic activity toward triple negative breast cancer cells.
However, like curcumin, PGB-0 has less solubility in water. To improve the solubility of PGB-0, we synthesized the aquoeus formulation of $\mathrm{PGB}-0$ with polyol sugar, sorbitol, namely PGB-0-So. As curcumin analogue, this compound is potential to be examined as an anti-cancer agent. In this study we aim to investigate the anti-metastatic activities of PGB-0-So against HER-2-overexpressed breast cancer cells.

\section{MATERIALS AND METHODS}

\section{Cell Cultures}

MCF-7/HER2 breast cancer cell lines were obtained from Prof. Masashi Kawaichi, Nara Institute of Science and Technology (NAIST), Japan. Cells were maintained with Dulbecco's Modified Eagle's Media (Gibco,New York,USA) high glucose supplemented by $10 \%$ Bovine Fetal Serum (Sigma-Aldrich, St. Leuis, USA), penicillinstreptomycin 1,5\% v/v (Gibco, New York, USA), Fungizone 0,5\% v/v (Gibco, New York, USA). Cells were incubated at $37^{\circ} \mathrm{C}$ with $5 \% \mathrm{CO}_{2}$. Samples used were sorbitol (Sigma-Aldrich, St. Leuis, USA), chemically synthesized Pentagamaboronon-0Sorbitol (PGB-0-So) (the purity is $\geq 93 \%$ ) was obtained from Cancer Chemoprevention Research Center (CCRC), Faculty of Pharmacy, Universitas Gadjah Mada and Doxorubicin (Sigma-Aldrich, St. Leuis, USA).

\section{Cytotoxicity Assay}

Cytotoxicity assay was conducted using MTT assay (Mosmann, 1983). Briefly, a 96-well microplate was seeded with 2x103 MCF-7/HER2 cells suspended in $100 \mu \mathrm{L}$ per well and incubated overnight. On the following day, the cells were treated with PGB-0-So at various concentration and incubated for 24 hours (h) at $37^{\circ} \mathrm{C}$ with $5 \% \mathrm{CO}_{2}$. Then, $100 \mu \mathrm{L}$ of $0.5 \mathrm{mg} / \mathrm{mL} 3$-(4,5-dimethylthiazzol2yl)-2,5-tidiphenyltetrazolium (MTT) reagent (Biovision, California, USA) were added and the cells were incubated for $2 \mathrm{~h}$. The reaction was 
stopped by adding SDS stopper solution containing $0.01 \mathrm{~N} \mathrm{HCl}$ and incubated overnight. The absorbance then being measured using a plate reader (BioRad, California, USA) at $595 \mathrm{~nm}$.

\section{Cell Migration Assay}

The $8.5 \times 10^{4}$ MCF-7/HER2 cells were seeded into 24-well plate and incubated for $24 \mathrm{~h}$. Cell starvation was performed by incubating cells on medium containing $0.5 \%$ FBS. Cells were scratched using a sterile yellow tip and treated with the different concentrations of PGB-0-So, are: $1 / 2 \mathrm{IC}_{50}$ $(18 \mu \mathrm{M}) ; 1 / 4 \mathrm{IC}_{50}(9 \mu \mathrm{M}) ; 1 / 8 \mathrm{IC}_{50}(4.5 \mu \mathrm{M}), 10 \mathrm{nM}$ doxorubicin or the combination of both for $24 \mathrm{~h}$. The closures of each scratched area were observed at $0,18,24$ and $42 \mathrm{~h}$ after treatment under inverted microscope (Olympus, Tokyo, Japan) and captured by a digital camera (Samsung ${ }^{\circledR}$, Seoul, South Korea). Then further analyzed using ImageJ $1.51 \mathrm{j} 8$ java 1.8.0_112 and IBM SPSS Statistics program.

\section{MMP-9 Protein Activity Assay}

The assay of MMP-9 activity in the MCF-7/ HER 2 culture media was performed using gelatin zymography. The culture media were obtained from the MCF-7/HER2 cells that were treated with estardiol (Sigma-Aldrich, St. Leuis, USA) in order to increase MMP-9 expression (Nilsson, et al., 2007), different concentrations of PGB-0-So, are: $1 / 2 \mathrm{IC}_{50}(18 \mu \mathrm{M}) ; 1 / 4 \mathrm{IC}_{50}(9 \mu \mathrm{M}) ; 1 / 8 \mathrm{IC}_{50}(4.5 \mu \mathrm{M})$, $10 \mathrm{nM}$ doxorubicin or the combination of them for $24 \mathrm{~h}$. Then, the culture media were subjected to $8 \%$ SDS-PAGE supplemented with $0.1 \%$ gelatin. Following the electrophoresis, gel was incubated with $2 \%$ of Triton-X 100 (Merck, New Jersey, USA) in water for 30 minutes at room temperature and the gel was then removed from solution. Furthermore, incubation buffer, consist of $40 \mathrm{mM}$ Tris- $\mathrm{HCl} \mathrm{pH} 8$, $10 \mathrm{mM} \mathrm{CaCl}_{2}, 0.02 \% \mathrm{NaN}_{3}$, was added to gel and incubated again at $37^{\circ} \mathrm{C}$ for $18-20 \mathrm{~h}$. Then, the gel was stained using Coomassie Brilliant Blue R-250 solution and de-stained until clear bands with blue background were observed. Those bands were documented and analyzed using Image J $1.51 \mathrm{j} 8 \mathrm{java}$ 1.8.0_112software.

\section{RESULTS}

\section{Cytotoxic Effect of PGB-0-So}

Characterization The compounds used in the cytotoxic assay in this study were sorbitol and PGB0 -So. Based on the correlation graph between the concentration of the compound and the precentage ofcell viability (Figure 1B), treatment with sorbitol did not show a decrease in the percent viability of MCF-7/HER2 cells, so it can be stated that sorbitol does not have cytotoxic effect on the cells. In contrast, PGB-0-So treatment at the concentrations of $2.96-59.22 \mu \mathrm{M}$ gave cytotoxic effects toward MCF-7/HER2 cells in a dose-dependent manner with $\mathrm{IC}_{50}$ value of $35 \mu \mathrm{M}$. The decreased viability of MCF-7/HER2 cells can also be seen from the changes of cell morphology after treatment with PGB-0-So for $24 \mathrm{~h}$ compared to the untreated group (Figure 1A).

\section{Anti-migratory Effect of PGB-0-So}

According to the cell migration assay, a single treatment of PGB-0-So and its combination with Dox were able to inhibit the migration of MCF-7/ HER2 cells (Figure 2A). At $42 \mathrm{~h}$ observation, a single treatment with a concentration of $1 / 8 \mathrm{IC}_{50}(4.5$ $\mu \mathrm{M})$ and $1 / 2 \mathrm{IC}_{50}(18 \mu \mathrm{M})$ PGB-0-So significantly inhibited cell migration compared to the control group with a percentage of closure of $58 \%$ and $71 \%$ (Figure 2B), respectively. At the same observation time $(42 \mathrm{~h})$, the combination treatment of $4.5 \mu \mathrm{M}$ or $18 \mu \mathrm{M}$ PGB-0-So with $10 \mathrm{nM}$ Dox also showed significant inhibition of cell migration compared to the control group with the percentages of closure of $47 \%$ and $46 \%$, respectively (Figure $2 \mathrm{~B}$ ).

\section{MMP-9 Activity}

MMP-9 activity analysis exhibited that a single PGB-0-So treatment and its combination with $10 \mathrm{nM}$ Dox were able to inhibit MMP-9 
A

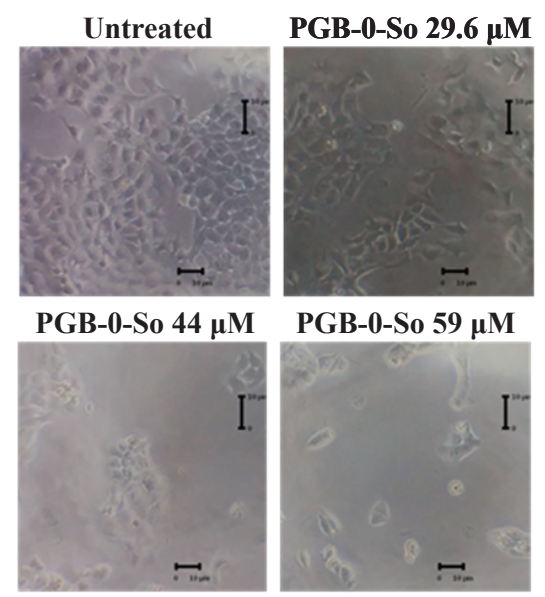

B

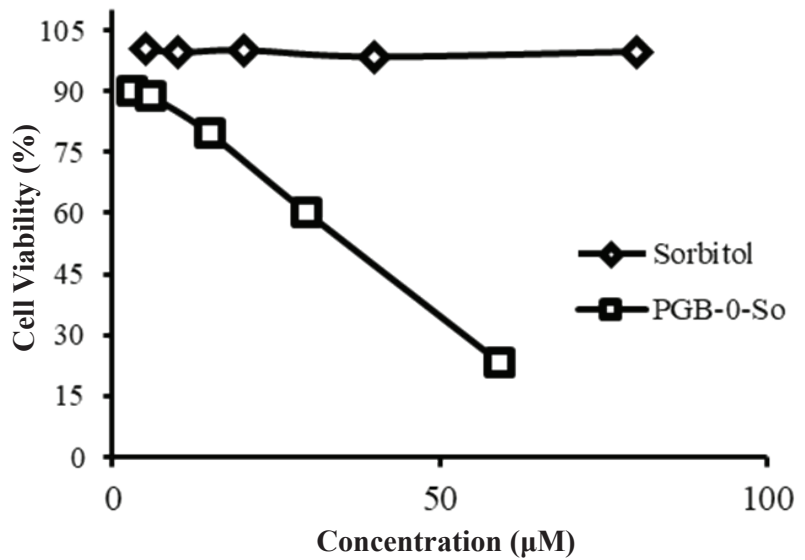

Figure 1. Cytotoxic effect of Pentagamaboronon-0-Sorbitol (PGB-0-So) toward MCF-7/HER2 cells. A: The cell morphology after treatment with PGB-0-So in various concentrations. B: Cytotoxic profile of Sorbitol and PGB0-So on MCF-7/HER2 cells describing correlation between concentration and cell viability. PGB-0-So performed cytotoxic effect with $\mathrm{IC}_{50}$ value of $35 \mu \mathrm{M}$.

activities (Figure 3A). At $24 \mathrm{~h}$ of treatment, PGB0 -So both single treatment and its combination with Dox inhibited MMP-9 activity in a dose-dependent manner when compared to the control group (Figure 3B). Thus, high concentration PGB-0-So has antimetastatic ability by inhibiting MMP-9 activity.

\section{DISCUSSION}

Cytotoxicity assay of PGB-0-So was conducted as early screening for this compound potency against MCF-7/HE2 cell lines. The results exhibited that the cytotoxic effect of PGB-0-So on MCF-7/HER2 cells was greater than that of PGB-0. PGB-0-So has an average value of $\mathrm{IC}_{50} 35 \mu \mathrm{M}$ while $\mathrm{IC}_{50}$ PGB-0 was still quite large, $270 \mu \mathrm{M}$ (Utomo, et al., 2017). This may be due to the increased solubility of PGB-0-So, since the solubility of a compound has an effect on its absorption and bioactivity in the body (Shangguan, et al., 2017). The cytotoxic activity of PGB-0 is probably caused by the interaction of the compound with ATP binding site of HER2 protein MCF-7/HER2 cells (Utomo, et al., 2017). With the increased cytotoxic effects of PGB-0-So on MCF-7/HER2 cells compared to PGB-0 it is thought to be due to other pathways involved in its cytotoxic activity, via the caveolae-mediated pathway. Caveolae is a protein on the surface of cell membranes that is reportedly able to interact specifically with sorbitol and contribute to the occurrence of endocytosis (Nguyen, et al., 2014). Caveolae is found to be overexpressed in most cancer cells (Patlolla, et al., 2004; Waalkes, et al., 2011) and one of them in breast cancer cells MCF-7 (Nguyen, et al., 2014). The presence of a specific interaction of sorbitol with the caveolae protein followed by endocytosis allows for increased cellular uptake of PGB-0-So into MCF-7/HER2 cancer cells, thus increasing the cytotoxic effect of the compound. However, for further research it is still necessary to test the mechanism of entry of PGB-0-So compounds into 
Indonesian Journal of Cancer Chemoprevention, October 2018

ISSN: 2088-0197

e-ISSN: $2355-8989$

iscic. $\mathrm{I}|\mathrm{J}| \mathrm{ClC}$

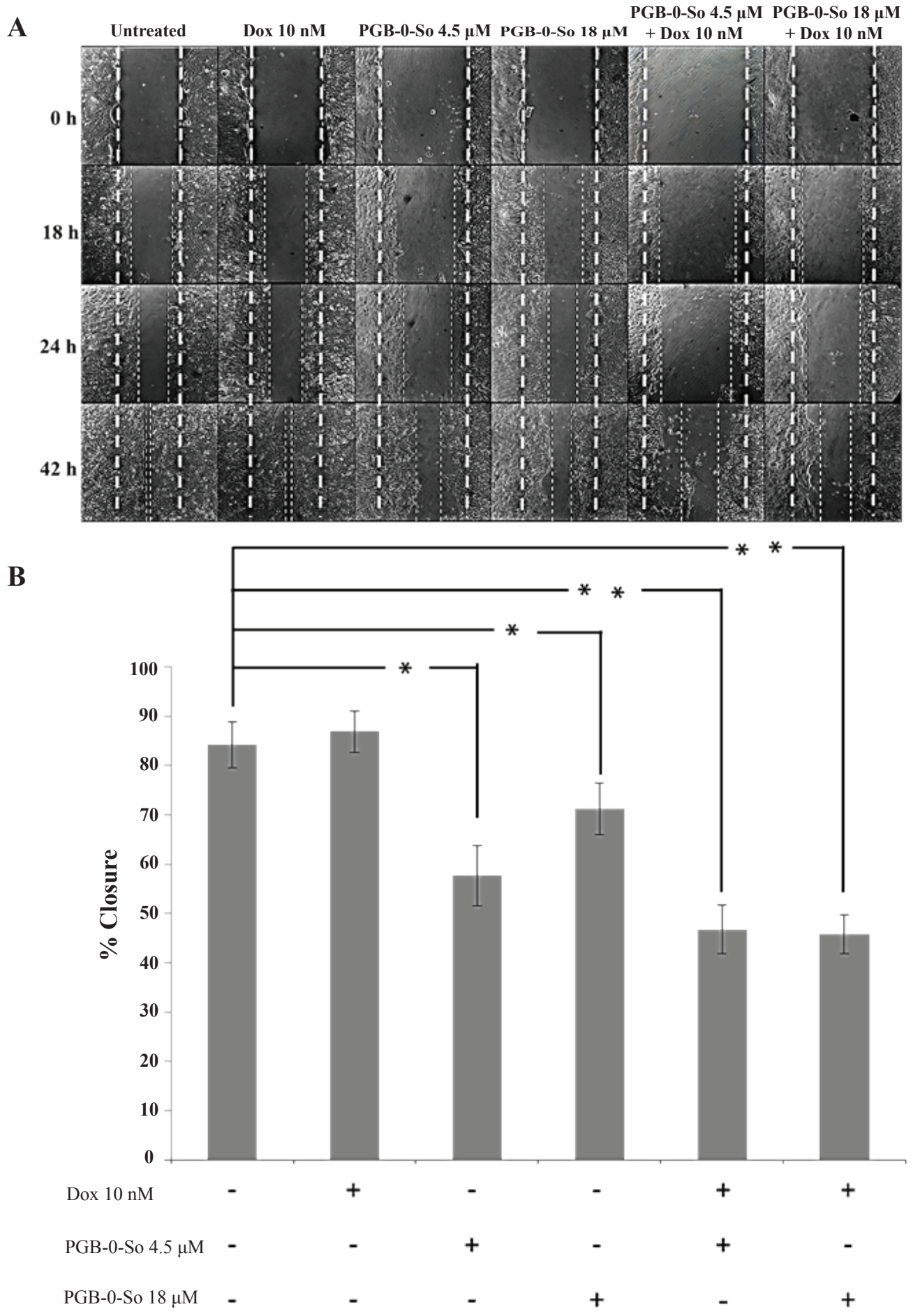

Figure 2. The effect of PGB-0-So cell migration toward MCF-7/HER2 cells. Cell migration assay was conducted using wound healing assay as described in the methods. A: Inhibitory activity of cell migration after treatment with $4.5 \mu \mathrm{M}, 18 \mu \mathrm{M}$ PGB-0-So, and its combination with $10 \mathrm{nM}$ Doxorubicin. B: Quantification of closure precentage on each treatment at $42 \mathrm{~h}$. Statistical analysis of \% closure on each treatment at $42 \mathrm{~h}\left({ }^{*} p<0.05\right)$ by ANOVA one way test compared to untreated cells. PGB-0-So exhibited inhibitory effect on cell migration at $4.5 \mu \mathrm{M}$ and 18 $\mu \mathrm{M}$ concentration either in single or combination with $10 \mathrm{nM}$ Doxorubicin at $42 \mathrm{~h}$. 
A

Dox $10 \mathrm{nM}$

PGB-0-So 4,5 $\mu \mathrm{M}$

PGB-0-So $9 \mu \mathrm{M}$

PGB-0-So $18 \mu \mathrm{M}$

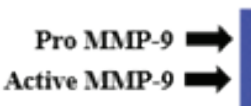

B

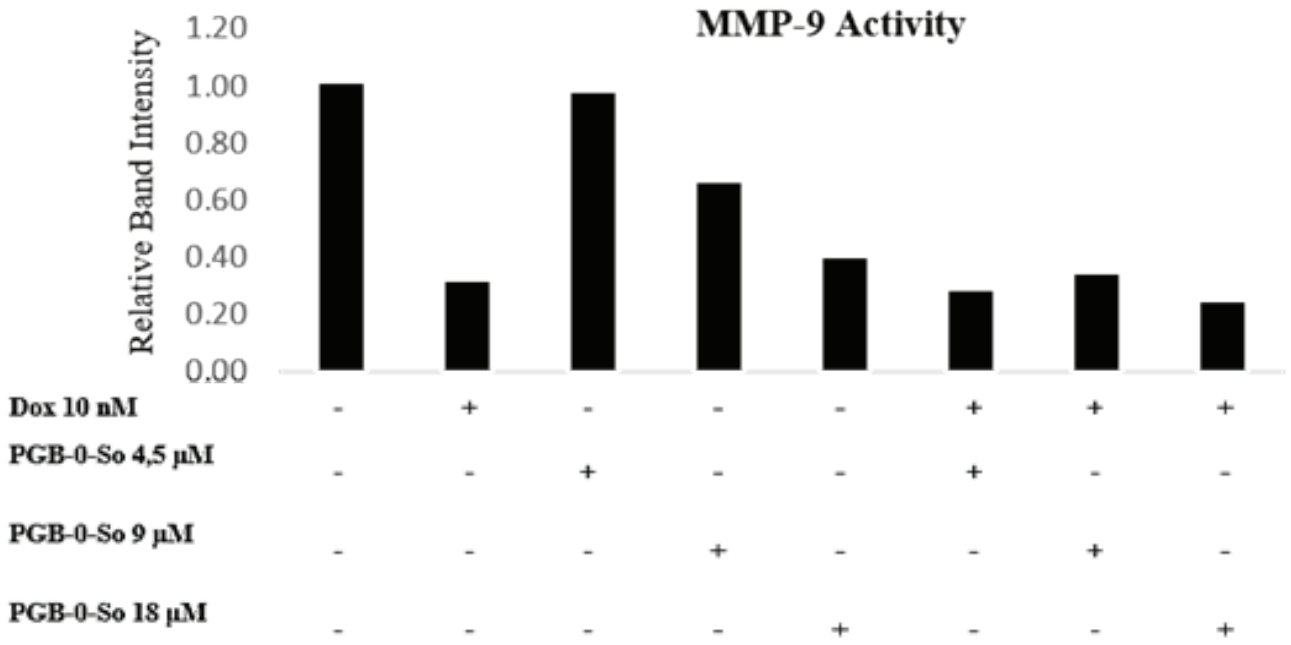

Figure 3. The effect of PGB-0-So on the MMP-9 Activity toward MCF-7/HER2 cells. Extracellular MMP-9 activity within medium was measured by analyzing MMP-9 activity using gelatin zymography assay as described in the methods. A: Band intensity of MMP-9 activity after treatment with PGB-0-So for $24 \mathrm{~h}$. B: Relative band intensity of MMP-9 activity. PGB-0-So showed the inhibiting of MMP-9 activity in single and combination with Doxorubicin $10 \mathrm{nM}$ after $24 \mathrm{~h}$ treatment.

cells to confirm the interaction of sorbitol from compounds with specific proteins on the surface of MCF-7/HER2 cells.

Furthermore, based on the cytotoxicity result, this study explored anti-metastatic activities of PGB-0-So. Anti-migratory effect of PGB-0-So was done using scratch wound healing assay. Based on this assay, PGB-0-So was combined with low concentration Dox $(10 \mathrm{nM})$, because low concentration Dox can trigger cell migration by inducing epithelial-mesenchymal transition (EMT) (Bandyopadhyay, et al., 2010). The results revealed that inhibition of cell migration by PGB-0-So, either in single or combination treatment with Dox. The statistical test $(p<0.05)$ on a 42 hour observation showed that PGB-0-So $4.5 \mu \mathrm{M}$ and $18 \mu \mathrm{M}$ concentrations in single or combination treatment with Dox significantly inhibited cell migration. The results of this study indicate that PGB-0-So was able to inhibit the activity of cell migration induced by Dox.

The anti-migratory effect of PGB-0-So is in line with research by Putri, et al. (2016) who reported anti-migration effect of the K-PGV-1, curcumin analogue, on 4T1 breast cancer cells. Curcumin was known to be able to inhibit the 
progression of MCF-7 breast cancer cell metastasis through decreasing of urocinase-type plasminogen activator (uPA) protein expression that plays a role sin extracellular molecular signalling in the cell migration process (Zong, et al., 2012). The results of Lin, et al. (2009) also showed an inhibition of migration of lung-cell lung (A549) by curcumin through suppressing MMP-2 and -9 expression via the ER-sinyaling pathway.

Matrix metalloproteinase (MMP) is known to play an important role in the invasion, metastasis and angiogenesis of cancer cells. One type of MMP playing important role in cell invasion is MMP-9 (Bandyophadyay, 2014). Kim, et al. (2012) have reported that curcumin is able to suppress expression of MMP-9 induced by 12-O-tetradecanoylphorbol13-acetate TPA on MCF-7 breast cancer cells. Therefore, to confirm migration inhibition through decreasing MMP-9 expression by PGB-0-So, the gelatin zymograph assay was performed. In this test, at each treatment was added estradiol in order to increase the resulting MMP-9 expression (Nilsson, et al., 2007).

The results showed that treatment for 24 and 48 hours with PGB-0-So $18 \mu \mathrm{M}$ concentration in single or combination treatment with Dox decreased MMP-9 activity. This result is in line with previous study that PGB-0 decreased MMP9 expression in 4T1 breast cancer cells (unplished data). The possible mechanism of inhibition of MMP-9 activity in this finding is through inhibiton of NF- $\mathrm{KB}$ activation, MMP-9 transcription factor. The previous research stated that curcumin inhibit MMP-9 activity through down-regulation of NF- $\kappa B$ and reduction of AP-1 activation (Kim et al., 2012). As an analog curcumin, the molecular mechanism of PGB-0-So in inhibiting MMP-9 activity is also expected via the NF-kB pathway.

\section{CONCLUSION}

PGB-0-So is potential to be developed as anti-cancer agent to prevent metastasis in HER2overexpressed breast cancer cells. .

\section{REFERENCES}

Amalina, N.D., Nurhayati, I.P., and Meiyanto, E., 2017, Doxorubicin Induces Lamellipodia Formation and Cell Migration, Indones. J. Cancer Chemoprev., 8(2), 61-67.

Bandyopadhyay, A., Wang, L., Agyin, J., Tang, Y., Lin, S., Yeh, I.T., et al., 2010, Doxorubicin in Combination with A Small TGFB Inhibitor: A Potential Novel Therapy for Metastatic Breast Cancer in Mouse Models, PLoS One, 5(4), e10365.

Bandyopadhyay, D., 2014, Farmer to Pharmacist: Curcumin as an Anti-invasive and Antimetastatic Agent for The Treatment of Cancer, Front. Chem., 2, 113.

Baribeau, S., Chaudhry, P., Parent, S., and Asselin, É, 2014, Resveratrol Inhibits Cisplatin-induced Epithelial-to-mesenchymal Transition in Ovarian Cancer Cell Lines, PloS One, 9(1), e86987.

Bhatnagar, B., Gilmore, S., Gloubeva, O., Pelser, C., Medeiros, M., Chumsri, S., et al., 2014, Chemotherapy Dose Reduction Due to Chemotherapy Induced Peripheral Neuropathy in Breast Cancer Patients Receiving Chemotherapy in the Neoadjuvantar Adjuvant Settings: A Single-center Experience, SpingerPlus, 3, 366.

Carvalho, C., Santos, R.X., Cardoso, S., Correia, S., Oliveira, P.L., Santos, M.S., et al., 2009. Doxorubicin: The Good, The Bad and The Ugly Effect. Current Med. Chem., 16(25), 3267-3286.

Kim, J.M., Noh, E.M., Kwon, K.B., Kim, J.S., You, Y.O., Hwang, J.K., et al., 2012, Curcumin Suppresses the TPA-induced Invasion Through Inhibition of PKCa-dependent MMP-expression in MCF7 Human Breast Cancer Cells, Phytomedicine, 19(12), 1085-1092.

Luque-Cabal, M., García-Teijido, P., FernándezPérez, Y., Sánchez-Lorenzo, L., and PalacioVázquez, I., 2016, Mechanisms Behind the Resistance to Trastuzumab in HER2-amplified Breast Cancer and Strategies to Overcome It., Clin. Med. Insights Oncol., 10(Suppl 1), 21-30.

Lin, S.S., Lai, K.C., Hsu, S.C., Yang, J.S., Kuo, C.L., Lin, J.P., et al., 2009. Curcumin Inhibits the Migration and Invasion of Human A549 Lung Cancer Cells Through the Inhibition of Matrix 
Metalloproteinase-2 and -9 and Vascular Endothelial Growth Factor (VEGF), Cancer Letters, 285, 127-133.

Meiyanto, E., Putri, D.D., Susidarti, R.A., Murwanti, R., Sardjiman, F.A., Husnaa, U., et al., 2014, Curcumin and Its Analogues (PGV-0 and PGV-1) Enhance Sensitivity of Resistant MCF-7 Cells to Doxorubicin Through Inhibition of HER2 and NFkB Activation, Asian Pac. J. Cancer Prev., 15(1), 179-184.

Mosmann, T., 1983. Rapid Colorimetric Assay for Cellular Growth and Survival: Application To Proliferation and Cytotoxicity Assays, J. Immunol. Methods, 65(1-2), 55-63.

Nguyen, K.C.T., Muthiah, M., Islam, M.A., Kalash, R.S., Cho, C.S., Park, H., et al., 2014, Selective Transfection with Osmotically Active Sorbitol Modified PEI Nanoparticles for Enhanced Anti-cancer Gene Therapy, Colloids Surf. B . Biointerfaces, 119, 126-136.

Nilsson, U.W., Garvin, S., and Dabrosin, C., 2007, MMP-2 and MMP-9 Activity is Regulated by Estradiol and Tamoxifen in Cultured Human Breast Cancer Cells, Breast Cancer Res. Treat., 102(3), 253-61

Patlolla, J.M., Swamy, M.V., Raju, J., and Rao, C.V., 2004, Overexpression of Caveolin-1 in Experimental Colon Adenocarcinomas and Human Colon Cancer Cell Lines, Oncology Rep., 11, 957-963.

Putri, H., Jenie, R.I., Handayani, S., Kastian, R.F., and Meiyanto, E., 2016, Combination of Potassium Pentagamavunon-0 and Doxorubicin Induces Apoptosis and Cell Cycle Arrest and Inhibits Metastasis in Breast Cancer Cells, Asian Pac. J. Cancer Prev., 17(5), 2683-2688.

Shangguan, L., Chen, Q., Shi, B., and Huang, F., 2017, Enhancing the Solubility and Bioactivity of Anticancer Drug Tamoxifen by Water-soluble Pillar[6]arene-based Host-guest Complexation, Chem. Commun., 53(70), 9749-9752.

Thorn, C.F., Oshiro, C., Marsh, S., HernandezBoussard, T., McLeod, H., Klein, T.T., et al., 2011, Doxorubicin Pathways: Pharmacodynamics and Adverse Effects, Pharmacogenet. Genomics, 21(7), 440-446.

Utomo, R.Y., Putri, H., Pudjono, P., Susidarti, R.A., Jenie, R.I., and Meiyanto, E., 2017, Synthesis and Cytotoxic Activity of 2,5-bis(4-boronic acid)benzylidine Cyclopentanone on HER2 Overexpressed-cancer Cells, Indonesian J. Pharm., 28, 74.

Waalkes, S., Eggers, H., Blasig, H., Atschekzei, F., Kramer, M.W., Hennenlotter, J., et al., 2011, Caveolin 1 mRNA is Overexpressed in Malignant Renal Tissue and Might Serve As a Novel Diagnostic Marker for Renal Cancer, Biomark Med., 5(2), 219-225.

Wolf-Yadlin, A., Kumar, N., Zhang, Y., Hauteniemi, S., Zaman, M., Kim, H., et al., 2006, Effects of HER2 Overexpression on Cell Signalling Networks Governing Proliferation and Migration, Mol. Sys. Biol, 2, 54-68.

Yokoyama, H., Ikehara, Y., Kodera, Y., Ikehara, S., Yatabe, Y., Mochizuki, Y., et al., 2006, Molecular Basis for Sensitivity and Acquired Resistance to Gefitinib in HER2-overexpressed Human Gastric Cancer Cell Lines Derived from Liver Metastasis, Br. J. Cancer, 95(11), 1504.

Zong, H., Wang, F., Fan, Q., and Wang, L., 2012. Curcumin Inhibits Metastatic Progression of Breast Cancer Cell Through Suppression of Urokinase-type Plasminogen Activator by NFkappa B Signaling Pathways, Mol. Biol. Rep., 39(4), 4803-4808. 